Article

\title{
Pyrolysis of Grape Marc from Tunisian Wine Industry: Feedstock Characterization, Thermal Degradation and Kinetic Analysis
}

\author{
Besma Khiari ${ }^{1}$ and Mejdi Jeguirim ${ }^{2, *(D)}$ \\ 1 Laboratoire des Sciences et Technologies de l'Environnement, University of Carthage, \\ BP 50 Borj Cedria Technopark, 2050 Hammam-Lif, Tunisia; besmakhiari@yahoo.com \\ 2 Institut de Sciences des Matériaux de Mulhouse, UMR 7661 CNRS, 15 rue Jean Starcky, \\ 68057 Mulhouse, France \\ * Correspondance: mejdi.jeguirim@uha.fr; Tel.: +33-389-608-661
}

Received: 7 March 2018; Accepted: 22 March 2018; Published: 23 March 2018

check for updates

\begin{abstract}
Despite the huge amounts of grape marc generated in Tunisia from the wine industry, very few efforts have been exerted to manage this harmful waste. Therefore, thermal processes may contribute to an environmental friendly management and also help winemakers to create new economic profitable circuits in an increasingly competitive context. Among the various thermochemical conversion process, pyrolysis is suitable for the recovery of food processing residues, due to their high minerals content and ability to create high added values of the derived products (biochar, bio-oil and syngas). In this context, the aim of this work is to optimize the pyrolysis process in order to benefit from the grape marc potential for achieving highest product yields. Therefore, physico-chemical and energy characteristics of grape marc issued from a Tunisian wine cooperative were determined according to international standards. Thermogravimetric analyzes were also performed to predict the grape marc behavior during degradation under an inert atmosphere. The profile of the mass loss rate shows two decomposition peaks corresponding to the cellulose and lignin decomposition. These peaks are shifted to lower temperatures comparing to several lignocellulosic biomass feedstocks due to high content of minerals that may play a catalytic role in the thermal degradation process. The biochar yield was about $40 \%$, which was never met in literature for agricultural biomass in slow pyrolysis. Such behavior may be attributed to high lignin content in grape marc. Activation energies were calculated using integral Flynn-Wall-Ozawa and Kissinger-Akahira-Sunose methods and differential Friedman method. The obtained values were $226.8,224.2$ and $229.5 \mathrm{~kJ} / \mathrm{mol}$, respectively. Such kinetics data are crucial in the design of the pyrolyzer for Tunisian grape marc recovery.
\end{abstract}

Keywords: grape marc; kinetic models; characterization; pyrolysis

\section{Introduction}

Grape is one of the most important fruit crops in the world with over 74 million tons produced annually [1]. Pressing grapes give juice, which is mostly for fermentation, and marc, which is also called pomace (solid product) [2], containing skins, seeds and stalks [3]. Although the pressing grape method depends strongly on the type of wine (white or red), Toscano et al. [3] described a general process giving the following proportions of grape products: $73 \%$ of juice and $27 \%$ of grape marc. The grape marc is distributed as follows: $19.5 \%$ of skins, $4.5 \%$ of seeds and $3 \%$ of stalks [3]. Grape marc may be processed further in distilleries in order to extract alcohol and the generated waste is called the exhausted grape marc residues. Wine cave (fresh grape marc) and alcohol distilleries (exhausted grape marc) produce large amounts of wastes, which are estimated at 7 million tons worldwide per year [4]. 
Grape marc characteristics depend strongly on the climatic conditions [5]. In general, grape marc is a wet ( $60 \%$ of moisture content) and heterogeneous waste [2]. Fresh grape marc are considered as a non-contaminated material with harmful characteristics, such as low $\mathrm{pH}$ and high organic matter $(90 \%)$, including phytotoxic and antibacterial phenolic substances [6]. The most common methods to recover these residues include production of alcohol, tartar, pharmaceuticals, cosmetics [6], feedstuff [7], yeast [8], extraction of phenolic compounds [9], production of oil [10] or energy [11], decontamination of effluents containing metals, such as copper and nickel [12], composting [13] and direct use as an organic fertilizer [14]. According to the European Council Regulation EC1493/1999 involving the common organization of wine market, fresh grape marc (except stalks) must be transferred to alcohol distilleries [6]. In Spain, several studies showed that exhausted grape marcs have a high content of lignin and tannin and are not easily digested. Therefore, they are not appropriate as nutritional supplements for animals. Besides, their high $\mathrm{C} / \mathrm{N}$ ratio limits their potential as soil fertilizers [14]. In this way, Italian laws (2010) require wine producers to send their wastes to distilleries [3]. Thus, some recovery methods are no longer permitted. In the same context, composting was also declared to not be economically viable in France and is gradually disappearing. Therefore, $60 \%$ of distilleries in France are using grape marc as combustible [4]. In fact, grape marc has interesting physical and thermal properties and energy contents [2,15]. However, a particular attention should be paid to the ash accumulation and pollutants emissions factors during grape marc combustion.

Similar to other Mediterranean countries, Tunisia is committed to finding a solution for environmental and economical disposal of their wastes and to participate further to reduce the global greenhouse effect. The wine industry in Tunisia generates annually about 25,000 tons of grape marc issued from internationally-known varieties, such as Grenache, Syrah, Cinsaut, Muscat of Alexandria, and from 54 aboriginal varieties, such as Razzegui, Tebourbi, Asli, Bazzoul Khaddem, Sakalsi, Garrat, Hamri, Chetoui and Chaouch. The grape plantations and the wine extraction processes are spread almost all over the country, although they are mainly located in the North East [16]. The discharge of the generated grape marc is usually centralized and seasonal in a short period of the year (August-October) [16]. Furthermore, only 10\% from the generated grape marc are used as nutritional ferment. A small part is used for compost production or dried and used as fertilizer [5]. The rest is either dumped or used as a traditional combustible in an uncontrolled manner, leading to the release of hazardous pollutants.

Currently, there is no sustainable strategy for the grape marc recovery in Tunisia. Recently, Kraiem et al. $[17,18]$ showed that despite suitable lower heating, high mineral contents and low bulk densities limit their direct use as biofuels in a combustion appliance for the residential heating sector. Authors had then resort to the densification and the blend of grape marc with woody biomass, which has low ash content $[17,18]$. However, combustion tests showed the high particular matter emissions, which limit the recovery of grape marc in domestic heating $[17,18]$. Therefore, the pyrolysis process could be a promising issue for the grape marc valorization since their mineral contents may be blocked in the residual char. This pyrolysis process could be interesting for wine, juice or jam-making industries $[19,20]$. However, as far as we know, a similar survey was never conducted in Tunisia, despite big potential gains. In fact, storage, handling and transport costs may be reduced with nearby, decentralized pretreatment establishments. Moreover, the pyrolytic gases can provide the power required for the endothermic pyrolysis process, ensuring self-sufficient operating system. In addition, the bio-oil and the biochar obtained from the pyrolysis process could be recuperated by winemakers for biofuels or soil amendments applications.

Consequently, the aim of this experimental work is to contribute to the understanding of the Tunisian grape marc behavior within an industrial processed pyrolysis. In particular, characteristics, including proximate and ultimate analyses, are determined. Thermogravimetric analyzes are also performed to predict the behavior of this waste during thermal degradation under different inert types of atmosphere. The obtained data are used for determining kinetic parameters that are subsequently used for determining the optimum pyrolysis process parameters. 


\section{Materials and Methods}

Grape marc used in this study was collected from a wine cooperative located in the north of Tunisia (Bou Argoub, Nabeul). The sample was fresh with $60 \%(\mathrm{wb})$ of moisture, which was reduced to $10 \%$. The sample was characterized through moisture content (EN 14774-1), ash content (EN 14775) and Low Heating Value, LHV (EN 14918) determination. Volatile matters and fixed carbon were determined using the Thermogravimetric analysis method [21]. Furthermore, elemental analysis was performed using a CHNOS analyzer (ThermoFisher Scientific, Villebon, France).

Thermogravimetric analyses (TGA) were carried out using a Mettler-Toledo TGA/DSC3+ (Mettler-Toledo, Columbus, OH, USA) thermobalance apparatus and repeated at least three times, with good reproducibility. The experiments were performed under nitrogen with flows of $12 \mathrm{Nl} \cdot \mathrm{h}^{-1}$ according to different linear heating programs $\left(5,10,20\right.$ and $\left.30^{\circ} \mathrm{C} / \mathrm{min}\right)$ in the range of $20-950{ }^{\circ} \mathrm{C}$.

\section{Kinetic Approach}

Many works have focused on the data analysis method for extracting reliable kinetic data from TGA experiments. There are three types of kinetic methods used for the analysis of biomass pyrolysis kinetics: differential, isoconversional, model-fitting and pseudo-components kinetics methods [22-25].

The fundamental rate equation used in all kinetic studies is generally described as:

$$
\frac{d X}{d t}=k(T) f(X)
$$

where $k$ is the rate constant and $f(X)$ is the reaction model that describes the reaction mechanism. The conversion rate $X$ is given by Equation (2):

$$
X=\frac{W_{0}-W_{t}}{W_{0}-W_{f}}
$$

where $W_{t}, W_{0}$, and $W_{f}$ are time $t$, initial and final weights of the sample, respectively.

The Arrhenius equation (Equation (3)) expresses the rate constant $k$ :

$$
k=A \exp \left(\frac{-E a}{R T}\right)
$$

where $E a$ is the activation energy $(\mathrm{kJ} / \mathrm{mol}), R$ is the universal gas constant $(8.314 \mathrm{~J} / \mathrm{K} \mathrm{mol}), A$ is the pre-exponential factor $\left(\mathrm{s}^{-1}\right)$ and $T$ is the absolute temperature $(K)$.

Energy activation is defined as the minimum energy requirement that must be overcome before molecules can get close enough to react and form products. Accordingly, the reactions with a high Ea need a high temperature or a long reaction time.

By combining Equations (1) and (3), we obtain:

$$
\frac{d X}{d t}=A \exp \left(\frac{-E a}{R T}\right) f(X)
$$

If the temperature is varied by a constant designed by $\beta$, which is the heating rate $\left(\beta=\frac{d T}{d t}\right)$, the introducing of $\beta$ in the Equation (4) gives:

$$
\frac{d X}{d T}=\frac{A}{\beta} \exp \left(\frac{-E a}{R T}\right) f(X) .
$$


By taking the logarithms of both sides of Equation (5), the first proposed differential Friedman method (Equation (6)) is obtained [26]:

$$
\operatorname{Ln} \frac{d X}{d t}=\operatorname{Ln}\left(\beta \frac{d X}{d T}\right)=\operatorname{Ln}[A f(X)]-\frac{E a}{R T} .
$$

If we rearrange Equation (6), we can obtain:

$$
L \frac{d X}{f(X)}=\frac{A}{\beta} \exp \left(\frac{-E a}{R T}\right) d T .
$$

After integrating Equation (7), it can be obtained:

$$
g(X)=\int_{0}^{X} \frac{d X}{f(X)}=\frac{A}{\beta} \int_{0}^{T} \exp \left(\frac{-E a}{R T}\right) d T
$$

By taking logarithms and using the Doyle approximation, Equation (8) can be rewritten as Equation (9). This equation is known as the Flynn-Wall-Ozawa method (FWO) [27]:

$$
\operatorname{Ln} \beta=\operatorname{Ln} \frac{A E a}{g(X) R}-2.315-\left(\frac{1.0516 E a}{R T}\right) .
$$

By using the derivation of Equation (3), and applying the logarithmic scale with the temperature data for each conversion rate $(X)$ at different heating rates $\left(\beta_{j}=\frac{d T}{d t}\right)$, the Kissinger method (KAS) calculates activation energy by plotting Equation (9) [28]:

$$
\operatorname{Ln} \frac{\beta}{T^{2}}=\operatorname{Ln} \frac{A R}{\operatorname{Eag}(X)}-\frac{E a}{R T} .
$$

The kinetic methods used in this study are Friedman, Flynn-Wall-Ozawa (FWO) and Kissinger-Akahira-Sunose (KAS) and their principles are listed in Table 1.

Table 1. Isoconversional Kinetic methods used in evaluating activation energy in this study.

\begin{tabular}{cccc}
\hline Method & Expression & Plots & Reference \\
\hline Friedman & $\operatorname{Ln} \frac{d X}{d t}=\operatorname{Ln}\left(\beta \frac{d X}{d T}\right)=\operatorname{Ln}[A f(X)]-\frac{E a}{R T}$ & $\operatorname{Ln}\left(\beta \frac{d X}{d T}\right)$ vs. $\frac{1}{T}$ & {$[26]$} \\
FWO & $\operatorname{Ln} \beta=\operatorname{Ln} \frac{A E a}{g(X) R}-2.315-\left(\frac{1.0516 E a}{R T}\right)$ & $\operatorname{Ln} \beta$ vs. $\frac{1}{T}$ & {$[27]$} \\
KAS & $\operatorname{Ln} \frac{\beta}{T^{2}}=\operatorname{Ln} \frac{A R}{\operatorname{Eag}(X)}-\frac{E a}{R T}$ & $\operatorname{Ln} \frac{\beta}{T^{2}}$ vs. $\frac{1}{T}$ & {$[28]$} \\
\hline
\end{tabular}

\section{Results and Discussions}

\subsection{Grape Marc Characterization}

Table 2 shows the proximate and ultimate analyses of the Tunisian grape marc. Moisture is reduced to $10 \%$, since it was very high after the wine extraction process $(60 \mathrm{wt} \%)$. Furthermore, the direct use of the grape marc has a negative effect on the thermochemical process efficiency and temperature [29]. 
Table 2. Proximate and ultimate analyses of grape marc.

\begin{tabular}{ccccc}
\hline & This Study & Miranda et al. [15] & Gonzalez-Vazquez et al. [30] & Makela et al. [31] \\
\hline Proximate Analysis & $\%$ & & & \\
Moisture $\mathrm{wb}$ & 10 & 7.49 & - & 1.4 \\
Fixed Carbon $\mathrm{db}^{\mathrm{db}}$ & 31.1 & 24.73 & 19.7 & - \\
Volatile matter $^{\mathrm{db}}$ & 55.6 & 67.80 & 67.6 & - \\
$\mathrm{Ash}$ db & 13.3 & 7.47 & 12.7 & 8.23 \\
LHV $^{\mathrm{db}}\left(\mathrm{MJ} \cdot \mathrm{kg}^{-1}\right.$ ) & 18.02 & 19.54 & 18.7 & 19.6 \\
\hline Elemental Analysis ${ }^{\mathrm{db}}$ & $\%$ & & 45.5 & 48.7 \\
$\mathrm{C}$ & 42.2 & 42.97 & 5.1 & 5.57 \\
$\mathrm{H}$ & 3.5 & 9.28 & 34.7 & 35.9 \\
$\mathrm{O}$ & 37.7 & - & 1.8 & 1.66 \\
$\mathrm{~N}$ & 3.0 & 2.05 & 0.17 & - \\
$\mathrm{S}$ & 0.3 & 0.17 &
\end{tabular}

The ash content is $13.3 \%$, which is higher than wood chips, at the same level as the grape marc was found by other authors, although this was lower than wheat straw [3]. The fixed carbon $(31.1 \%)$ is higher than the value obtained by Miranda et al. (25\%) for grape marc and higher than several biomass resources, such as olive husk (19\%) and pine sawdust (17\%). However, as expected, the volatile matter $(55.6 \%)$ is lower than the grape marc of Miranda et al. $(67.8 \%)$, olive husk $(76 \%)$ and pine sawdust (69\%) [15,32-34]. The high ash and fixed carbon contents confirm that slow pyrolysis is the suitable thermochemical conversion process for the grape marc recovery. In particular, the char yield (fixed carbon fix and ash contents) was about $44.4 \%$, which was never met in literature for agricultural biomass under slow pyrolysis conditions. This feature distinguishes Tunisian grape marc from European ones and even from Chinese and American pomace. Many factors can explain these differences, such as local wine making practices and Tunisian grapevine specificity. The pyrolytic char derived from the Tunisian grape marc may have several applications, including soil amendment, adsorbents, biocoal, etc.

Elemental analysis also shows some differences with values met in literature, although this is consistent with the wide range of biomass composition that would undergo efficient pyrolysis. Carbon, hydrogen and oxygen are lower than the mean reported values, while $\mathrm{N}$ and $\mathrm{S}$ are quite high. This repartition is close to the composition of grape skins, although it is quite different from that of its seeds or stalks [32-34]. If nitrogen remains in char, this would be a supplementary argument in favor of pyrolysis against combustion, as biochar can be used as nutrients for soils.

\subsection{Thermal Degradation of Grape Marc under Inert Atmosphere}

The thermal degradation of biomass feedstocks was well described in the literature, which serves the main purpose of ensuring that from an energy standpoint, the pyrolysis process is self-sufficient [24-28,33,35]. Many factors affect the kinetic parameters based on the processing of TGA data, including processing conditions; heat and mass transfer limitations; physical and chemical heterogeneity of the sample; and systematic errors.

Figure 1 shows the mass loss $(X)$ and the derivative (DTG) of mass loss $(d X / d t)$ curves obtained during the pyrolysis of Tunisian grape marc. Thermogravimetric analysis could evaluate the thermal behavior of fuels under an inert atmosphere. The results are helpful in the fundamental understanding of biomass fuels when developing biomass utilization for the pyrolysis plant. 


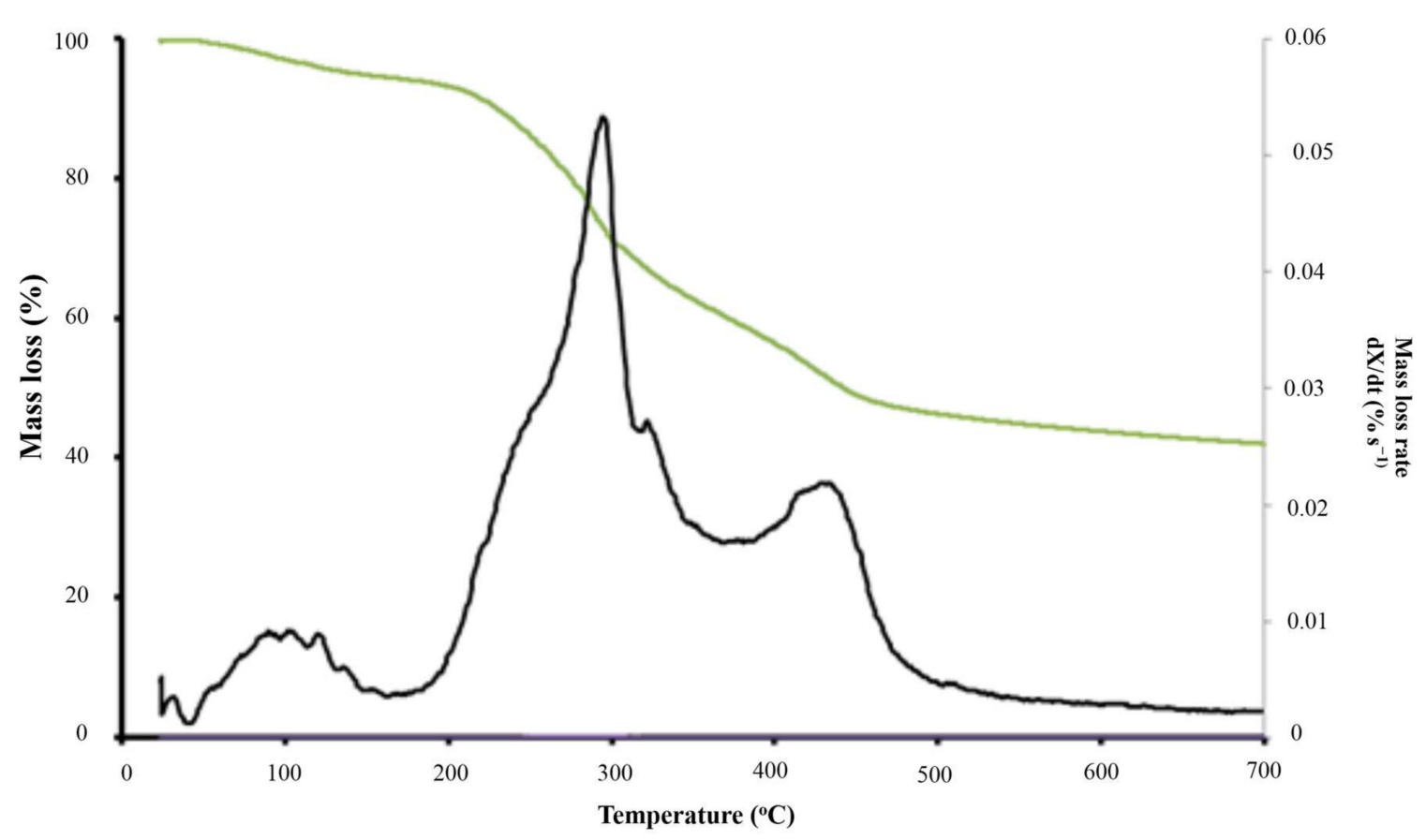

Figure 1. TG and DTG curves of Grape Marc under an inert atmosphere at $5{ }^{\circ} \mathrm{C} / \mathrm{min}$.

The shape of Derivative Thermo-Gravimetric (DTG) curve includes three regions in ascending order of temperature variation, corresponding to three degradation steps. The first region occurred between 23 and $166^{\circ} \mathrm{C}$, which corresponds to the biomass drying by moisture loss and the departure of light volatiles. The second region corresponds to the devolatilization step, which occurs between $166^{\circ} \mathrm{C}$ and $500{ }^{\circ} \mathrm{C}$. This step was called in the literature as the active pyrolysis includes two zones. The first one occurs between 166 and $362{ }^{\circ} \mathrm{C}$, which corresponds to the decomposition of cellulose and hemicellulose. A clear peak at $288^{\circ} \mathrm{C}$ is attributed to the decomposition of cellulose with an overall maximum rate of $0.055 \% \cdot \mathrm{s}^{-1}$. A second zone occurs between $362{ }^{\circ} \mathrm{C}$ and $500{ }^{\circ} \mathrm{C}$, which corresponds to the lignin degradation. After the devolatilization step, a third step of passive pyrolysis is observed. This step characterized by a low and a continuous mass loss rate corresponds to the end of lignin degradation as well as char formation and rearrangement.

Several phenomena occur within grape marc pyrolysis and to varying extents: cracking, reforming, dehydration, condensation, polymerization and even oxidation and gasification reactions, which take place after the release of the oxygen and the vapors present in the product.

The obtained TG data, $T$ (temperature), $X$ (mass loss), $T_{\text {peak }}$ (peak temperature), $d X / d t$ (mass loss rate) and $R_{M}$ (mean reactivity) are shown in Table 3. One may remind that reactivity is calculated as follows:

$$
R_{M}=100 \sum\left(\frac{R_{\text {peak }}}{T_{\text {peak }}}\right) .
$$

The comparison of the obtained values with those found in literature for various lignocellulosic biomass feedstocks shows several differences. First, the peak temperature obtained at $288^{\circ} \mathrm{C}$ is lower than the reported peak temperatures for cellulose decomposition, which is between 310 and $320^{\circ} \mathrm{C}$. Furthermore, this is lower than the peak temperature of $332{ }^{\circ} \mathrm{C}$ for pure cellulose [36] and for various lignocellulosic biomass in the literature [22,35,37]. However, this peak was at $261^{\circ} \mathrm{C}$ for palm kernel shells for example [38]. The high content of minerals initially present in the Tunisian grape marc [20,21] is thought to be responsible for the shift to lower levels of temperatures as they may play a catalyzing role in the process. The impact of these minerals, especially $\mathrm{Na}, \mathrm{K}$ and $\mathrm{Mg}$, were evidenced in previous investigations [39]. 
Table 3. TG under inert atmosphere $\left(5^{\circ} \mathrm{C} / \mathrm{min}\right)$.

\begin{tabular}{cccc}
\hline \multirow{2}{*}{ Pyrolysis Zone } & $T\left({ }^{\circ} \mathrm{C}\right)$ & $166-750$ \\
\cline { 2 - 4 } & & $X(\%)$ & $94.5-41.3$ \\
\hline \multirow{3}{*}{ Zone 1 } & $T\left({ }^{\circ} \mathrm{C}\right)$ & $166-362$ \\
& & $X(\%)$ & $94.5-61.2$ \\
Active Pyrolsis & & $T_{\text {peak } 1}\left({ }^{\circ} \mathrm{C}\right)$ & 288 \\
& \multirow{2}{*}{ Zone 2 } & $R_{1}\left(\% \cdot \mathrm{s}^{-1}\right)$ & 0.032 \\
\cline { 2 - 4 } & & $T\left({ }^{\circ} \mathrm{C}\right)$ & $362-500$ \\
& & $X(\%)$ & $64.81-46.4$ \\
& & $T_{\text {peak } 2\left({ }^{\circ} \mathrm{C}\right)}$ & 423 \\
& & $R_{2}\left(\% \cdot \mathrm{s}^{-1}\right)$ & 0.021 \\
\hline \multirow{2}{*}{ Passive Pyrolysis } & & $R_{M} \times 10^{3}\left(\% \cdot \mathrm{s}^{-1} \cdot{ }^{\circ} \mathrm{C}^{-1}\right)$ & 0.14 \\
\hline & & $T\left({ }^{\circ} \mathrm{C}\right)$ & $500-750$ \\
& & $X(\%)$ & $46.4-41.3$ \\
\hline
\end{tabular}

Hemicellulose decomposition is identified through the shoulder between 238 and $257{ }^{\circ} \mathrm{C}$, which is in the interval of $195-306{ }^{\circ} \mathrm{C}$. Such behavior is well-known in the literature and the hemicellulose decomposition step appears usually as a more or less pronounced shoulder instead of a well-defined peak [38]. Similar to cellulose decomposition, during the grape marc thermal degradation, hemicellulose decomposition occurs at a lower temperature due to the catalytic effect of alkali and alkali-earth metals [39].

The lignin degradation step also shows a clear difference compared to the usual shape of the DTG curve of lignocellulosic biomasses. In particular, the DTG curve of the Tunisian grape marc shows a specific region occurring between 362 and $500{ }^{\circ} \mathrm{C}$, with a peak at $425^{\circ} \mathrm{C}$ that yields an overall rate around $0.021 \% \cdot \mathrm{s}^{-1}$. This peak is attributed to the high contents of lignin. Otherwise, the zone corresponding to the cracking of the polymeric structure of $\mathrm{C}-\mathrm{C}$ or $\mathrm{C}-\mathrm{O}-\mathrm{C}$ bonds in lignin would result in only a flat tailing section. Generally, the thermal degradation of lignocellulosic biomass is not characterized by a sharp peak for lignin decomposition.

The reactivity value $\left(0.14 \times 10^{-3} \% \cdot \mathrm{s}^{-1} \cdot{ }^{\circ} \mathrm{C}^{-1}\right)$ is in the same magnitude as those of various biomasses, such as the coffee husk around $0.19 \times 10^{-3} \% \cdot \mathrm{s}^{-1} \cdot{ }^{\circ} \mathrm{C}^{-1}$ [38] or palm residues $\left(0.23 \times 10^{-3} \% \cdot \mathrm{s}^{-1} \cdot{ }^{\circ} \mathrm{C}^{-1}\right)[40]$ for the same heating rate.

The char yield of $39.68 \%$ is expected in view of the proximate analysis, although this is higher than any agricultural waste. The char resulting from the first stages also probably contributed to the secondary reactions, which mainly occurred by catalyzing cracking and polymerization reactions that promoted recombination reactions among the volatile species to yield more condensed char structures [39].

In order to extract the kinetic parameters of the thermal degradation of Tunisian grape marc under pyrolysis conditions, the impact of different heating rates was investigated. Figure 2 showed that increasing the heating rate leads to a shift in the peak temperature towards higher values together with higher mass loss rates. Indeed, when heating rate is increased from 5 to $30{ }^{\circ} \mathrm{C} / \mathrm{min}$, the maximum peak temperature moves from 288 to $322^{\circ} \mathrm{C}$. The explanation is that the material reaches the cracking temperature in a shorter time when higher heating rates are considered. Due to the heat and mass transfer limitations inside the particle, these higher heating rates are a consequence of inner temperature gradients. In fact, increasing the reactor temperature ramp does not allow good temperature stabilization within the grape marc, which causes a delay in the volatile matter departure. The same behavior has been reported in the literature for numerous biomasses [40-42]. 


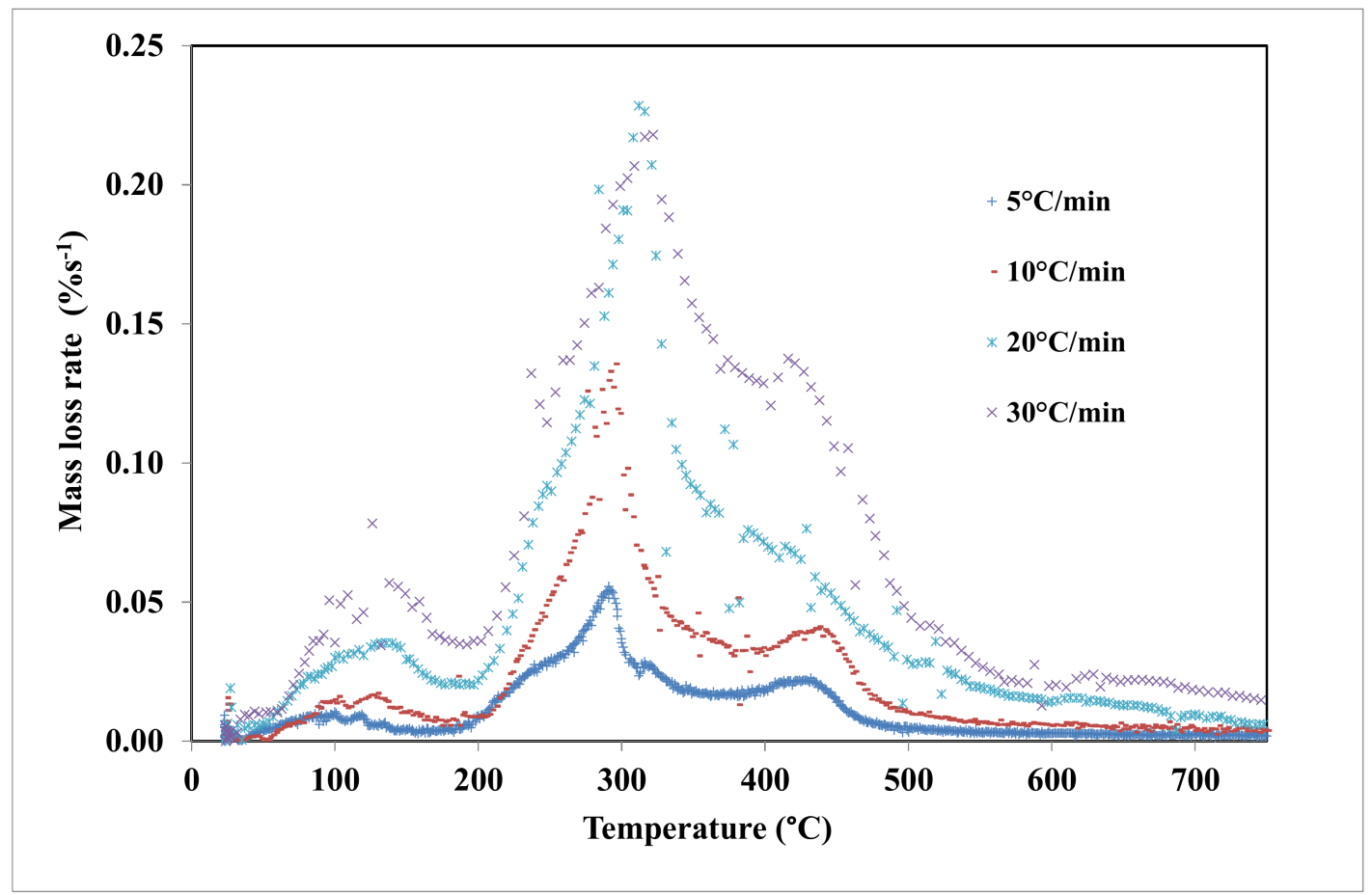

Figure 2. Mass loss rate for different heating rates.

\subsection{Kinetic Study}

The linear plots of KAS, FWO and Friedman are shown in Figure 3. As the initial mass loss is attributed to the moisture loss, the first conversion rate selected to determine the kinetic parameters is 0.2 , while the final point is taken at 0.65 . Above this value, no good determination coefficients were obtained, which may be attributed to the complexity of the char production and rearrangement.

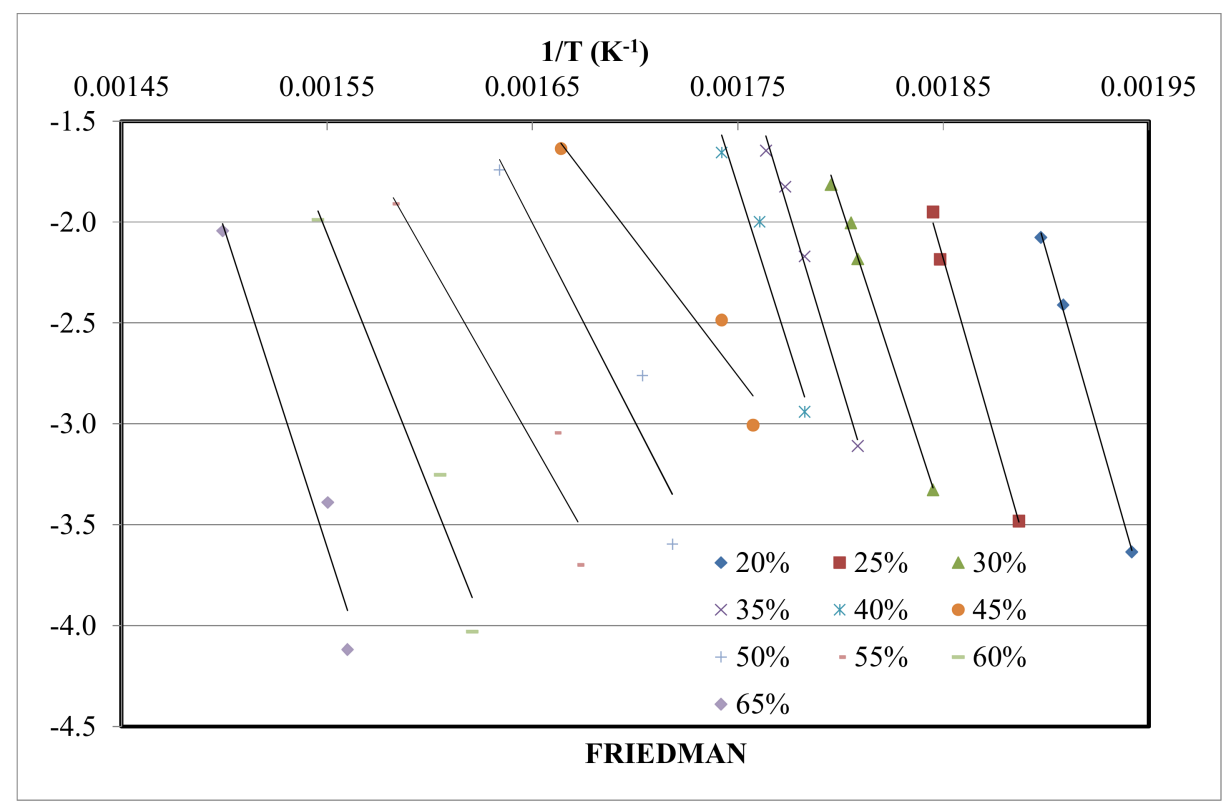

(a)

Figure 3. Cont. 


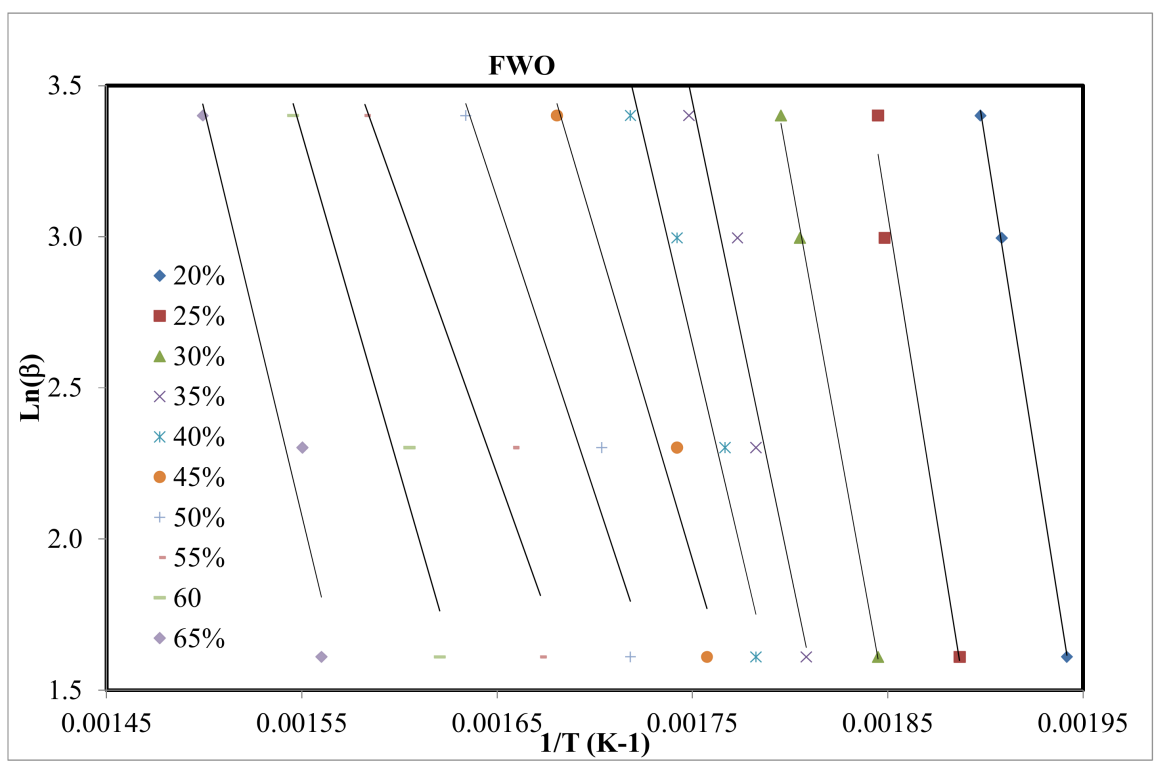

(b)

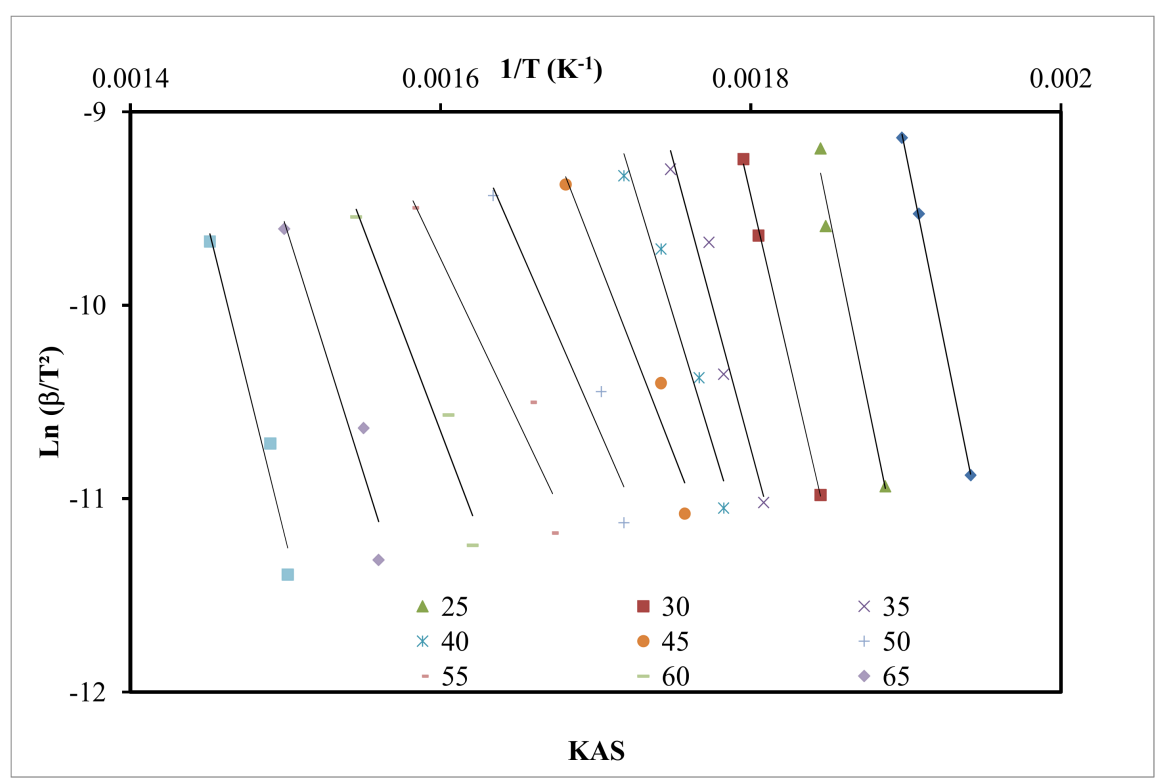

(c)

Figure 3. Plots for kinetic models. (a) Friedman; (b) FWO; (c) KAS.

The calculated corresponding values are presented for each conversion ratio in Table 4 . The mean activation energy values for GM with the use of the KAS, FWO and Friedman methods were 224.2, 226.8 and $229.5 \mathrm{~kJ} / \mathrm{mol}$, respectively. Table 4 depicts that the activation energy decreases when the conversion increases. It is assumed that a good biomass thermal degradation meets low activation energy values. In the initial stages and for KAS, FWO and Friedman methods, the $E a$ values were high $(333.3,323.3$ and $295.9 \mathrm{~kJ} / \mathrm{mol}$, respectively, at $X=0.2)$. However, these values gradually decrease as the conversion rate $X$ goes up until it reaches $55 \%$, before increasing again (an exception point around $45 \%$ is probably due to an experimental error). This phenomenon was not reported in other works, where $E a$ was decreasing continuously, for several cellulosic biomasses $[43,44]$. This is explained by the quick and first scission of the weakly bonded amorphous cellulose and hemicelluloses. Once all-crystalline cellulose has decomposed, lignin accounted for a further decrease in activation energy [44]. 
Table 4. Calculated Energy activation with $R^{2}$ values from Friedman, FWO and KAS models (E, kJ/mol).

\begin{tabular}{ccccccc}
\hline \multirow{2}{*}{$\boldsymbol{X}$} & \multicolumn{2}{c}{ Friedman } & \multicolumn{2}{c}{ FWO } & \multicolumn{2}{c}{ KAS } \\
\cline { 2 - 7 } & $\boldsymbol{E} \boldsymbol{a}$ & $\boldsymbol{R}^{\mathbf{2}}$ & $\boldsymbol{E} \boldsymbol{a}$ & $\boldsymbol{R}^{\mathbf{2}}$ & $\boldsymbol{E} \boldsymbol{a}$ & $\boldsymbol{R}^{\mathbf{2}}$ \\
\hline 0.20 & 295.9 & 0.999 & 323.3 & 0.999 & 333.3 & 0.999 \\
0.25 & 295.0 & 0.995 & 316.9 & 0.979 & 324.4 & 0.978 \\
0.30 & 259.2 & 0.995 & 282.0 & 0.999 & 287.4 & 0.999 \\
0.35 & 280.5 & 0.991 & 244.4 & 0.947 & 247.7 & 0.943 \\
0.40 & 267.5 & 0.955 & 217.0 & 0.964 & 218.8 & 0.961 \\
0.45 & 111.4 & 0.947 & 172.1 & 0.959 & 171.3 & 0.954 \\
0.50 & 163.8 & 0.911 & 154.5 & 0.948 & 157.6 & 0.941 \\
0.55 & 148.5 & 0.936 & 142.9 & 0.939 & 140.0 & 0.930 \\
0.60 & 212.3 & 0.965 & 176.9 & 0.962 & 175.3 & 0.958 \\
0.65 & 262.2 & 0.959 & 212.1 & 0.941 & 212.1 & 0.935 \\
\hline Mean & \multicolumn{2}{c}{229.5} & \multicolumn{2}{c}{226.8} & \multicolumn{2}{c}{224.2} \\
\hline \multicolumn{6}{c}{}
\end{tabular}

In our case and according to previous studies [2-5,14,31,41], lignin content in grape marc is much higher than cellulose. Consequently, the whole pyrolysis is thought to be mainly controlled by the lignin and its intermediate products.

In another hand, it is noticed that the activation energy for grape marc is greater than the values obtained for the pyrolysis of lignin $[45,46]$ and other biomass [32,47-50]. These activation energies are high even when compared to other grape marc that originated from Italy. Fiori et al. found values between 171 and $178 \mathrm{~kJ} / \mathrm{mol}$ for heating rates between 3 and $30^{\circ} \mathrm{C} / \mathrm{min}$ [51].

The isoconversional methods were applied to four different experimental data sets $(5,10,20$ and $30{ }^{\circ} \mathrm{C} / \mathrm{min}$ ). The results are presented in Figure 4 . KAS and FWO are very close. The calculated $E a$ at the different conversion levels can be attributed to a different macro-component decomposition. At low conversion levels (0.2-0.3), the activation energies between 250 and $340 \mathrm{~kJ} / \mathrm{mol}$ can be regarded as being related to hemicelluloses degradation. The lower $E a$ in the range of $140-240 \mathrm{~kJ} / \mathrm{mol}$ are obtained for the conversion levels of 0.25 and 0.50 , which can be attributed to cellulose cracking. The activation energy increases to $212 \mathrm{~kJ} / \mathrm{mol}$ for KAS and OFW models and to 262 for the Friedman model at higher conversion levels, for which lignin is thought to be responsible. At higher temperatures, activation energies decrease, which may be explained by an overlapping of cellulose and lignin continuing degradation as well as by char rearrangement through secondary and more complex reactions, which was found in literature [52-55].

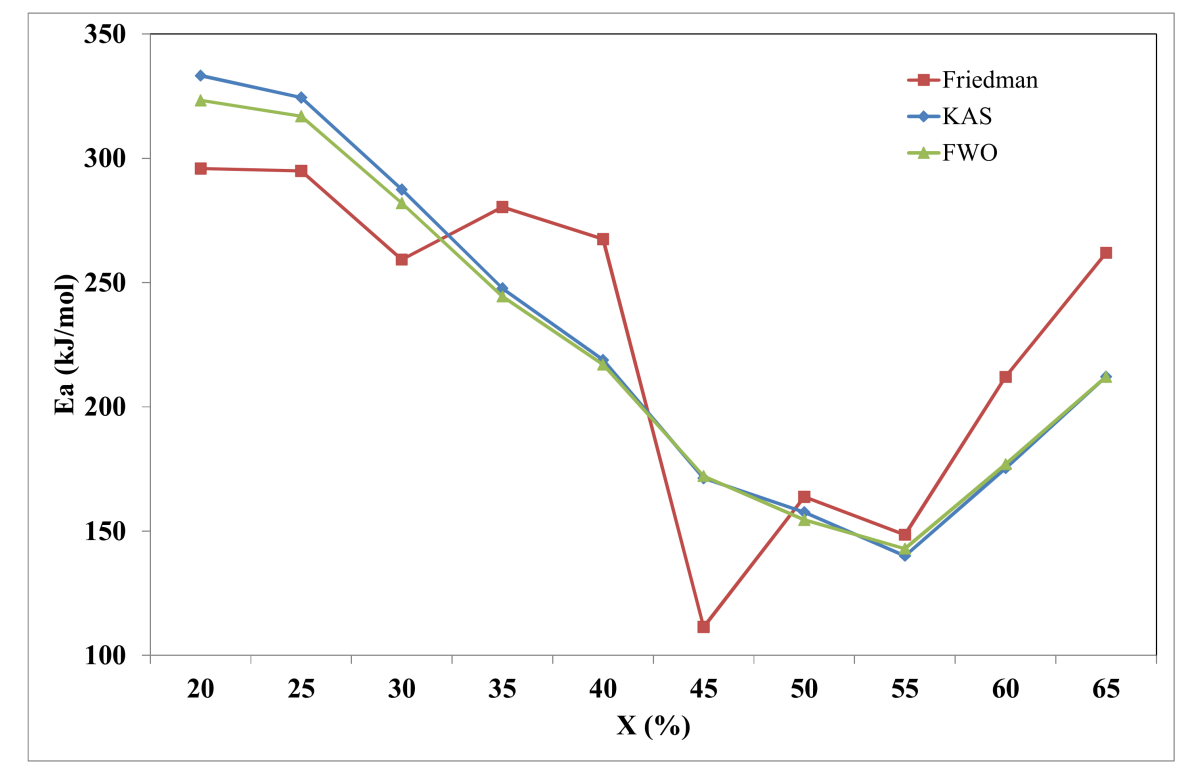

Figure 4. Activated Energies for Friedman, FWO and KAS method for conversion from 20 to $65 \%$. 


\section{Conclusions}

In these times, where the circular economy is at the service of the economic actors, the slow pyrolysis of grape marc can be an advantage in the wine industry and distilleries on more than one level, especially in the Tunisian context. Furthermore, as better environmental management of grape marc is increasingly necessary, this study is required to achieve a better understanding of the economics of grape marc pyrolysis for bio-fuel production and for resolving issues related to the capabilities of this technology in practical applications. Indeed, the pyrolysis process applied to these residues provides a high biochar yield of around $40 \%$, which was never reached by any other agricultural waste. This fact is explained by the inhibition of hemicellulose and cellulose decomposition on one hand and by high lignin content on the other hand. With the same aim to improve some characteristics of grape marc by increasing its bulk density and reducing its ash content, densification and blending with woody biomass can help to solve the problem. The biochar is interesting as it may be used as nutritional ferment for soils or may undergo direct and efficient gasification. Minerals, which were an obstacle in combustion operations, become a major asset in pyrolysis. Furthermore, their presence played a catalytic role and shifted the cracking temperatures to lower values, thus reducing the operation cost.

To optimize this and to achieve high energy recovery from grape marc, kinetics data were calculated and helped in the design of pyrolysis reactors for grape marc. Integral and differential methods used in the frame of this work showed very close and reliable kinetic parameters.

Author Contributions: All authors contributed equally to the work done.

Conflicts of Interest: The authors declare no conflict of interest.

\section{Nomenclature}

$\begin{array}{ll}A & \text { pre-exponential factor }\left(\mathrm{s}^{-1}\right) \\ E a & \text { activation energy }(\mathrm{kJ} / \mathrm{mol}) \\ k & \text { rate constant }\left(\mathrm{s}^{-1}\right) \\ R & \text { universal gas constant }(\mathrm{J} / \mathrm{K} \text { mol }) \\ R_{M} & \text { mean reactivity }\left(\% \cdot \mathrm{s}^{-1} \cdot{ }^{\circ} \mathrm{C}^{-1}\right) \\ t & \text { time }(\mathrm{s}) \\ T & \text { absolute temperature }(\mathrm{K}) \\ T_{\text {peak }} & \text { peak temperature }(\mathrm{K}) \\ W_{0} & \text { initial weight of the sample }(\mathrm{mg}) \\ W_{f} & \text { final weight of the sample }(\mathrm{mg}) \\ W_{t} & \text { time t weight of the sample }(\mathrm{mg}) \\ X & \text { mass loss }(\%) \\ \beta & \text { heating rate }(\mathrm{K} / \mathrm{s})\end{array}$

\section{References}

1. Moncayo, J.R.; Aurand, J.M. Table and Dried Grapes; Food and Agriculture Organisation (FAO): Rome, Italy, 2016; ISBN 978-92-5-109708-3.

2. Celma, A.R.; Rojas, S.; Lopez-Rodriguez, F. Waste-to-energy possibilities for industrial olive and grape by-products in Extremadura. Biomass Bioenergy 2007, 31, 522-534. [CrossRef]

3. Toscano, G.; Riva, G.; Duca, D.; Pedretti, E.F.; Corinaldesi, F.; Rossini, G. Analysis of the characteristics of the residues of the wine production chain finalized to their industrial and energy recovery. Biomass Bioenergy 2013, 55, 260-267. [CrossRef]

4. Dwyer, K.; Hosseinian, F.; Rod, M. The Market Potential of Grape Waste Alternatives. J. Food Res. 2014, 3, 91-106. [CrossRef]

5. Souza, E.C.; Uchoa-Thomaz, A.M.A.; Carioca, J.O.B.; Lima, A.; Martin, C.G.; Alexandrino, C.D.; Ferreira, P.A.T.; Rodrigues, A.L.M.; Rodrigues, S.P.; Silva, J.N.; et al. Chemical composition and bioactive compounds of grape pomace (Vitis vinifera, L.), Benitaka variety, grown in the semiarid region of Northeast Brazil. Food Sci. Technol, Campinas 2014, 34, 135-142. [CrossRef] 
6. Bustamante, M.A.; Moral, R.; Paredes, C.; Perez-Espinosa, A.; Moreno-Caselles, J.; Pérez-Murcia, M.D. Agrochemical characterisation of the solid by-products and residues from the winery and distillery industry. Waste Manag. 2008, 28, 372-380. [CrossRef] [PubMed]

7. Vaccarino, C.; Tripodo, M.M.; Lo Curto, R.B.; Cimino, G. The effects of NaOH treatments of grape-marc, vinasse, and wheat-straw mixtures on their degradability in vitro. Bioresour. Technol. 1993, 44, 197-202. [CrossRef]

8. Lo Curto, R.B.; Tripodo, M.M. Yeast production from virgin grape marc. Bioresour. Technol. 2001, 78, 5-9. [CrossRef]

9. Louli, V.; Ragoussis, N.; Magoulas, K. Recovery of phenolic antioxidants from wine industry by-products. Bioresour. Technol. 2004, 92, 201-208. [CrossRef] [PubMed]

10. Xu, C.; Zhang, Y.; Wang, J.; Lu, J. Extraction, distribution and characterisation of phenolic compounds and oil in grapeseeds. Food Chem. 2010, 122, 688-694. [CrossRef]

11. Kabir, M.J.; Chowdhury, A.A.; Rasul, M.G. Pyrolysis of Municipal Green Waste: A Modelling, Simulation and Experimental Analysis. Energies 2015, 8, 7522-7541. [CrossRef]

12. Villaescusa, I.; Fiol, N.; Martinez, M.; Miralles, N.; Poch, J.; Serarols, J. Removal of copper and nickel ions from aqueous solutions by grape stalks wastes. Water Res. 2004, 38, 992-1002. [CrossRef] [PubMed]

13. Bertran, E.; Sort, X.; Soliva, M.; Trillas, I. Composting winery waste: Sludges and grape stalks. Bioresour. Technol. 2004, 95, 203-208. [CrossRef] [PubMed]

14. Bustamante, M.A.; Pérez-Murcia, M.D.; Paredes, C.; Moral, R.; Pérez-Espinosa, A.; Moreno-Caselles, J. Short-term carbon and nitrogen mineralisation in soil amended with winery and distillery organic wastes. Biores. Technol. 2007, 98, 3269-3277. [CrossRef] [PubMed]

15. Miranda, M.T.; Arranz, J.I.; Román, S.; Rojas, S.; Montero, I.; López, M. Characterization of grape pomace and pyrenean oak pellets. Fuel Process Technol. 2011, 92, 278-283. [CrossRef]

16. Agence Nationale de Gestion des Déchets-ANGED. Strategic Options for the Promotion of Value of Organic Waste VDO Tunisia; Agence Nationale de Gestion des Déchets: Tunis, Tunisie, 2009.

17. Kraiem, N.; Lajili, M.; Limousy, L.; Said, R.; Jeguirim, M. Energy recovery from Tunisian agri-food wastes: Evaluation of combustion performance and emissions characteristics of green pellets prepared from tomato residues and grape marc. Energy 2016, 107, 409-418. [CrossRef]

18. Jeguirim, M.; Kraiem, N.; Lajili, M.; Guizani, C.; Zorpas, A.; Leva, Y.; Michelin, L.; Josien, L.; Limousy, L. The relationship between mineral contents, particle matter and bottom ash distribution during pellet combustion: Molar balance and chemometric analysis. Environ. Sci. Pollut. Res. Int. 2017, 24, 9927-9939. [CrossRef] [PubMed]

19. Brassard, P.; Godbout, S.; Raghavan, V.; Palacios, J.H.; Grenier, M.; Zegan, D. The Production of Engineered Biochars in a Vertical Auger Pyrolysis Reactor for Carbon Sequestration. Energies 2017, 10, 288. [CrossRef]

20. Yang, X.; Wang, H.; Strong, P.J.; Xu, S.; Liu, S.; Lu, K.; Sheng, K.; Guo, J.; Che, L.; He, L.; et al. Thermal Properties of Biochars Derived from Waste Biomass Generated by Agricultural and Forestry Sectors. Energies 2017, 10, 469. [CrossRef]

21. Jeguirim, M.; Elmay, Y.; Limousy, L.; Lajili, M.; Said, R. Devolatilization behavior and pyrolysis kinetics of potential Tunisian biomass fuels. Environ. Prog. Sustain. Energy 2014, 33, 1452-1458. [CrossRef]

22. Mishra, R.K.; Mohanty, K. Pyrolysis kinetics and thermal behavior of waste sawdust biomassusing thermogravimetric analysis. Biores. Tech. 2018, 25, 63-74. [CrossRef] [PubMed]

23. White, J.E.; Catallo, W.J.; Legendre, B.L. Biomass pyrolysis kinetics: A comparative critical review with relevant agricultural residue case studies. J. Anal. Appl. Pyrol. 2011, 9, 11-33. [CrossRef]

24. Cepeliogullar, O.; Haykiri Acma, H.; Yaman, S. Kinetic modelling of RDF pyrolysis: Model-fitting and model-free approaches. Waste Manag. 2016, 48, 275-284. [CrossRef] [PubMed]

25. Bartocci, P.; Anca Couce, A.; Slopiecka, K.; Nefkens, S.; Evic, N.; Retschitzegger, S.; Barbanera, M.; Buratti, C.; Cotana, F.; Bidini, G.; et al. Pyrolysis of pellets made with biomass and glycerol: Kinetic analysis and evolved gas analysis. Biomass Bioenergy 2017, 97, 11-19. [CrossRef]

26. Friedman, H.L. Kinetics of thermal degradation of char-forming plastics from thermogravimetry. Application to a phenolic plastic. J. Polym. Sci. Polym. Symp. 1964, 6, 183-195. [CrossRef]

27. Flynn, J.H.; Wall, L.A. General treatment of thermogravimetry of polymers. J. Res. NBS A Phys. Chem. 1966, 70, 487-523. [CrossRef] 
28. Kissinger, H.E. Variation of peak temperature with heating rate in differential thermal analysis. J. Res. Natl. Bur. Stand. 1956, 57, 217-221. [CrossRef]

29. Guizani, C.; Jeguirim, M.; Valin, S.; Limousy, L.; Salvador, S. Biomass Chars: The Effects of Pyrolysis Conditions on Their Morphology, Structure, Chemical Properties and Reactivity. Energies 2017, 10, 796. [CrossRef]

30. González-Vázquez, M.P.; Garcia, R.; Pevida, C. Optimization of a Bubbling Fluidized Bed Plant for Low-Temperature Gasification of Biomass. Energies 2017, 10, 306. [CrossRef]

31. Makela, M.; Kwong, C.W.; Bostrom, M.; Yoshikawa, K. Hydrothermal treatment of grape marc for solid fuel applications. Energy Convers. Manag. 2017, 145, 371-377. [CrossRef]

32. Arvelakis, S.; Koukios, E.G. Physicochemical upgrading of agroresidues as feedstocks for energy production via thermochemical conversion methods. Biomass Bioenergy 2002, 22, 331-348. [CrossRef]

33. Limousy, L.; Jeguirim, M.; Dutournié, P.; Kraiem, N.; Lajili, M.; Said, R. Gaseous products and particulate matter emissions of biomass residential boiler fired with spent coffee grounds pellets. Fuel 2013, 107, 323-329. [CrossRef]

34. Gamzenur, O.; Ayse Eren, P. Kinetics and evolved gas analysis for pyrolysis of food processing wastes using TGA/MS/FT-IR. Waste Manag. 2017. [CrossRef]

35. ElSayed, S.A.; Khairy, M. Effect of heating rate on the chemical kinetics of different biomass pyrolysis materials. Biofuels 2015, 6, 157-170. [CrossRef]

36. Orfao, J.J.M.; Antunes, F.J.A.; Figueiredo, J.L. Pyrolysis kinetics of lignocellulosic materials of three independent reactions model. Fuel 1999, 78, 349-358. [CrossRef]

37. ElSayed, S.A.; Mostafa, M.E. Kinetic Parameters Determination of Biomass Pyrolysis Fuels Using TGA and DTA Techniques. Waste Biomass Valoriz. 2015, 6, 401-415. [CrossRef]

38. Jeguirim, M.; Bikai, J.; Elmay, Y.; Limousy, L.; Njeugna, E. Thermal characterization and pyrolysis kinetics of tropical biomass feedstocks for energy recovery. Energy Sustain. Dev. 2014, 23, 188-193. [CrossRef]

39. Haddad, K.; Jeguirim, M.; Jellali, S.; Guizani, C.; Delmottea, L.; Bennicia, S.; Limousy, L. Combined NMR structural characterization and thermogravimetric analyses for the assessment of the AAEM effect during lignocellulosic biomass pyrolysis. Energy 2017, 134, 10-23. [CrossRef]

40. El may, Y.; Jeguirim, M.; Dorge, S.; Trouvé, G.; Said, R. Study on the thermal behavior of different date palm residues: Characterization and devolatilization kinetics under inert and oxidative atmospheres. Energy 2012, 44, 702-709. [CrossRef]

41. Yuan, H.; Xing, S.; Huhetaoli, L.T.; Chen, Y. Influences of copper on the pyrolysis process of demineralized wood dust through thermogravimetric and PyeGC/ MS analysis. J. Anal. Appl. Pyrolysis 2015, 112, 325-332. [CrossRef]

42. Jeguirim, M.; Dorge, S.; Trouvé, G. Thermogravimetric analysis and emission characteristics of two energy crops in air atmosphere: Arundo donax and Miscanthus giganthus. Bioresour. Technol. 2010, 101, 788-793. [CrossRef] [PubMed]

43. Skreiberg, A.; Skreiberg, O.; Sandquist, J.; Sorum, L. TGA and macro-TGA characterisation of biomass fuels and fuel mixtures. Fuel 2011, 90, 2182-2197. [CrossRef]

44. Chouchene, A.; Jeguirim, M.; Khiari, B.; Zagrouba, F.; Trouvé, G. Thermal degradation of olive solid waste: Influence of particle size and oxygen concentration. Resour. Conserv. Recycl. 2010, 54, 271-277. [CrossRef]

45. Rhén, C.; Ohman, M.; Gref, R.; Wasterlund, I. Effect of raw material composition in woody biomass pellets on combustion characteristics. Biomass Bioenergy 2007, 1, 66-72. [CrossRef]

46. Chouchene, A.; Jeguirim, M.; Trouvé, G.; Favre-Reguillon, A.; Le Buzit, G. Combined process for the treatment of olive oil mill wastewater: Absorption on sawdust and combustion of the impregnated sawdust. Bioresour. Technol. 2010, 101, 6962-6971. [CrossRef] [PubMed]

47. Jahirul, M.I.; Rasul, M.G.; Chowdhury, A.A.; Ashwath, N. Biofuels Production through Biomass PyrolysisA Technological Review. Energies 2012, 5, 4952-5001. [CrossRef]

48. Ghouma, I.; Jeguirim, M.; Guizani, C.; Ouederni, A.; Limousy, L. Pyrolysis of Olive Pomace: Degradation Kinetics, Gaseous Analysis and Char Characterization. Waste Biom. Valoriz. 2017, 8, 1689-1697. [CrossRef]

49. Jun-Ho, J.; Seung-Soo, K.; Ye-Eun, L.; Yeong-Seok, Y. Pyrolysis Characteristics and Kinetics of Food Wastes. Energies 2017, 10, 1191. [CrossRef]

50. McKendry, P. Energy production from biomass (part 1): Overview of biomass. Bioresour. Technol. 2002, 83, 37-46. [CrossRef] 
51. Ghetti, P.; Ricca, L.; Angelini, L. Thermal analysis of biomass and corresponding pyrolysis products. Fuel 1996, 75, 565-573. [CrossRef]

52. Fiori, L.; Valbusa, M.; Lorenzi, D.; Fambri, L. Modeling of the devolatilization kinetics during pyrolysis of grape residues. Biores. Tech. 2012, 103, 389-397. [CrossRef] [PubMed]

53. Marculescu, C.; Ciuta, S. Wine industry waste thermal processing for derived fuel properties improvement. Renew. Energy 2013, 57, 645-652. [CrossRef]

54. Di Blasi, C. Modeling chemical and physical processes of wood and biomass pyrolysis. Prog. Energy Combust. Sci. 2008, 34, 47-90. [CrossRef]

55. Wang, P.; Bret, H.; Howard, B.H. Impact of Thermal Pretreatment Temperatures on Woody Biomass Chemical Composition, Physical Properties and Microstructure. Energies 2018, 11, 25. [CrossRef]

2018 by the authors. Licensee MDPI, Basel, Switzerland. This article is an open access article distributed under the terms and conditions of the Creative Commons Attribution (CC BY) license (http:// creativecommons.org/licenses/by/4.0/). 